\title{
LX. Letter from Dr. Delaville to M. Vauquelin, upon the oxidation of metals, and particularly of lead
}

\section{Dr. Delaville}

To cite this article: Dr. Delaville (1806) LX. Letter from Dr. Delaville to M. Vauquelin, upon the oxidation of metals, and particularly of lead, Philosophical Magazine Series 1, 25:100, 365-367, DOI: $10.1080 / 14786440608563466$

To link to this article: http://dx.doi.org/10.1080/14786440608563466

Published online: 18 May 2009.

Submit your article to this journal $₫$

ЏII Article views: 2

Q View related articles $\square$ 
On the Oxidation of Melals, particularly of Lead. 365

exhibited a greenish colour, gas being given out from both wires, which also were turned black.

These two experiments led me strongly to conceive that an alkali must bave been formed during the operations, seeing that alkalis produce precisely the same effects : to prove this, I restored the blue colour of the litmus by a few drops of dilute sulphuric acid, thinking that the acid would combine with the alkali formed; which was the case: it was again submitted to galvanic action, which effected a change of the blue colour, and the production of a green as before.

Taking a fresh quantity recently made, $I$ changed its co* lour to red with the above acid, and, on galvanizing it in the same manner, had the pleasing satisfaction to find that the red became very soon blue in consequence of a production of alkali which must have saturated the acid.

Having repeated these experiments several times with the same results, I was fully satisfied as to the formation of an alkali ; but wanting more proof, to a portion of the infusion of litmus, which had been turned green, I added a few drops of the sulphate of iron, a slight precipitation of which in the state of a red oxide took place : this is always the case when an uncombined alkali is present. Syrup of violets diluted with an equal quantity of distilled water, and galvanized with silver or iron wires, turned as perfectly green as it could have done on the addition of pure ammonia, potash, or soda. If these facts are in the least new or interesting, by their insertion in your valuable magazine you will much oblige,

Yours respectfully,

City Dispensary,

D, GARDNEIR. Grocer's-Hall Court, Poultry, 20th Sept. 1806.

IX. Letter from Dr. Delaville to M. Vauquelin, upon the Oxidation of Metals, and particularly of Lead*.

I Have been some time in the habit of pursuing, as often as my other occupations would permit, some experiments

* From Annales de Chimie, tom. lviii. p. 52. 


\section{6ิ6 On the Oxidation of Metals, patticularly of Lead.}

upon the oxidation of metals, and particularly that of lead, and as the results I obtained were of a nature sufficiently encouraging to induce me to proceed in my researches, I request that, if you are of the same opinion, you will give that degree of publicity to them you may think proper.

We kuow that upon rinsing a glass bottle with a little water and lead (small shot), the friction soon detaches small portions of the lead, which, being suspended in the water, give it at first a slate colour; if the agitation is a little longer continued, the water becomes grayish, and a little longer still, it becornes whitish, until at last it is of a very fine white.

This oxide of lead has such a tendency to unite with carbonic acid, that when exposed to the open air, upon being taken out of the water, it becomes almost immediately covered with a pellicle of a brilliant whiteness, which seems to be nothing else than carbonate of lead.

This oxide of lead remains always under water without experiencing any sensible alteration, either in the shade or in the light; but if, when it is inclosed in a crystal bottle full of atmospheric air, and containing a small quantity of water, there is any of it sticking to the inside of the bottle above the level of the water, and if the bottle is exposed to the rays of the sun, in this case the portion of oxide exposed to the light will be seen to pass successively to the yellow, and from the yellow to the red, and thus furnish masticot and minium.

This white oxide exposed in a glass capsule to the heat of a fire, soon passes from the white to the yellow, and from the yellow to the red, in the same manner as that which was exposed to the light.

This oxide may be made in great quantity, and at a small exp̀ense, and on this account render some preparations less costly in which it may be employed; it may be also made use of in painting.

The following is the method I had recourse to in order to obtain this oxide: I inclosed a quantity of lead (small shot) in a leaden barrel, into which $I$ poured about one fifth of water; I allowed the rest of the capacity of the barrel to be filled with atmospheric air, and I turned the barrel round by 
On the Oxidation of Metals, particularly of Lead. $\quad 367$ means of an axis adjusted at its two extremities. Every one knows how easy it is to turn round a machine of this kind by means of a water-mill.

In order to procure a continual supply of fresh air in the barrel, I contrived to introduce at various points in its circumference leaden tubes open at both their extremities, and which almost met in the centre of the barrel in the form of radii ; the other end of these tubes protruded a few inches from the outside of the barrel, to which they were soldered at their junction with it so closely as not to admit of any water escaping.

You will find in the box I have sent you a little bottle, numbered 1., containing oxide of lead, prepared as above, and which has never yet been taken out of the water.

In No. 2. there are pieces of oxide dried in the air in a glass capsule; the brilliant white surface of it was exposed to the air of a room during its desiccation, and the porous and dirty white surface was that which was in contact with the glass of the capsule.

In No. 3. there is the same oxide hanging to the end of the tube, and become yellow, then red, by simple exposure to the light of the sun. The tube is sealed hermetically, and filled partly with water and partly with atmospheric air.

InNo.4. is the same oxide, hanging in a tube hermetically sealed, also filled partly with water and partly with air, exposed for a very long time to the light on one side, but coated on the other with a mixture of wax and lamp-black.

No. 5. is a small bottle, containing oxide of lead agitated with water and carbonic acid gas.

If you find the present results worthy your attention, I shall communicate to you the further progress of my experiments.

I have given the, name of oxide to No. 1. I think it is an oxide, but it does not appear to be a common one: I would have examined it with more attention, but it required more time than I can at present spare. 